\title{
ACUTE PARANITRANILINE POISONING
}

\author{
BY
}

\section{A. ANDERSON}

From The Anglo-Iranian Oil Company, Ltd., Iran.

Paranitraniline (para-nitro-amido-benzene) has not been the subject of extensive toxicological investigation although it has been included in several inquiries into the properties of the aniline group. It occurs in the form of a fine yellow powder and is employed in the manufacture of dyes and explosives and in the textile industry. Kobert and Rambousek (1913) state that the para-isomer is more toxic than the meta-, though Lewis et al. (1920) found the meta- to be the more dangerous; while Hunter (1944) considers that paranitraniline is more toxic than aniline itself. The modes of entry into the body are by inhalation and by absorption through the skin, and either appears to be enhanced by a moist, warm environment. Brandt (1943) puts the maximum allowable concentration in air for aniline during an 8-hour exposure at 5 p.p.m., but it is known that nitration of an aromatic compound increases its toxicity, and, therefore, the allowable concentration for paranitraniline should be less than this figure.

\section{Symptomatology and Treatment}

The symptoms of acute paranitraniline poisoning begin with headache, flushing of the face, restriction of breathing, and occasionally nausea and vomiting. If exposure continues the headache becomes violent, and tinnitus, vertigo, and extreme respiratory distress may ensue. There is generalized muscular weakness, somnolence, irritability, and an intense violetcoloured cyanosis, especially of the ears, lips, nose, tongue, fingers, and toes. After the lapse of some hours a yellowish pigmentation of the soles of the feet and the palms of the hands appears, spreading gradually to other parts of the body. If coma supervenes the case is in grave danger, and death may occur in a convulsive state. The pulse is rapid and thready, the respiration rate raised, while the temperature and blood pressure tend to be lowered in the early stages. Methaemoglobinaemia is the essential pathological change, and Hamblin and Mangelsdorff (1938), over a period of two years, found a constant correlation between the concentration of methaemoglobin in the blood and the severity of the clinical syndrome.

The cardinal principles in the treatment of acute paranitraniline poisoning are removal from contact, removal of the contaminated clothing, and bathing the patient. It is of the utmost importance that all clothing should be removed as soon as possible and that bathing is thorough, otherwise absorption via the skin will continue. Oxygen is of considerable assistance, but it will be found that the mild or moderately severe case tends to recover spontaneously. Rest is essential and exertion should be avoided as this markedly increases the respiratory distress. Intravenous injection of a 1 per cent. solution of methylene blue affords considerable relief, possibly because methylene blue is a powerful hydrogen acceptor, and thus liberates intramolecular oxygen in the tissues.

\section{Report of an Incident}

Towards the end of 1943 a ship docked at a port in the Persian Gulf. Part of the cargo was paranitraniline packed in wooden kegs, a number of which had been broken during the voyage, resulting in one of the ship's holds becoming coated with the yellow dye in the form of a fine powder.

During the night a shift of Persian dock labourers was engaged in unloading the unbroken kegs and cleaning out the hold. Cleaning was performed in the Oriental manner of squatting on the heels and sweeping with hard brooms. In consequence the air became heavily laden with paranitraniline, which was inhaled freely by the sweepers. Their skins and clothing also became covered with the dust. The shift ceased work at about 6 a.m. At mid-day seven of these labourers attended hospital, all presenting the same syndrome in varying degree, one of them being unconscious. They complained of intense headache, somnolence, weakness, and respiratory distress. Their lips, the tips of their ears, tongue, finger-tips, toes, and to a lesser extent, their faces and bodies, were mulberry coloured. Their clothing was stained with yellow powder. The pulse in most cases was regular, but rapid and of poor volume, the blood pressure was normal and the respiration rate was raised to about 26 per minute in all cases. Respiratory distress became most marked on slight effort. None of the patients vomited.

Three of the more severely affected were admitted to hospital, two conscious, and the third unconscious, though he was restless and irritable, and resented interference. The unconscious patient had his spleen enlarged to four finger breadths below the costal margin, and liver to two finger breadths with a hard and easily palpable edge. The upper limit of liver dullness was in the seventh intercostal space. The two conscious patients were admitted because of intense headache, extreme dyspnoea, and deep cyanosis.

A concentrated solution of methylene blue in 
sterile distilled water was prepared and $10 \mathrm{ml}$. administered intravenously to each patient. The results were immediate. The unconscious patient vomited mucous material stained bright yellow by the dye, and regained consciousness sufficiently to ask for water. Five minutes after the injection the conscious patients volunteered the information that their headache had almost gone, and the relief of their respiratory difficulty was obvious. Nausea and a little retching occurred in both cases, but it is thought that if the injection had been given more slowly this might have been avoided.

In spite of the relief of subjective symptoms the cyanosis remained unchanged for about half an hour. It disappeared slowly, however, over a period of 12 hours, by the end of which time the two conscious patients had fully recovered.

The unconscious patient was less fortunate. An hour after the injection of methylene blue solution, which was given at about 4.30 p.m., he was answering simple questions. The following morning he was still conscious but had developed marked jaundice accompanied by pyrexia, tachycardia, albuminuria, and haematuria. The blood urea was $137 \mathrm{mg}$. per $100 \mathrm{ml}$. No malarial parasites were found in the peripheral blood, although he undoubtedly had a malarial hepatitis and splenitis. In spite of all efforts, he died at 2 a.m. on the morning of the third day, about 36 hours after admission to hospital or 50 hours after the commencement of his eight hours' exposure. Religious objections prevented the performance of a necropsy.

The ship was visited about three hours after these cases were first seen, and several of the European crew were found to be suffering mildly from the effects of paranitraniline absorption, notably the 'bosun,' who had been supervising the cleaning operations from the hatch. None of the Europeans had been in the hold, but there had been a heavy cloud of the dust over the fore end of the ship. The Master was ignorant of the hazard involved, and no warning had been issued to him. The nature of the powder was only discovered after the ship's papers were inspected. The kegs were not marked in any way, and there was no other indication that their contents were poisonous. There had been similar cases at a port of call some days previously, when the same hold had been open and unbroken kegs were unloaded. The hold was subsequently washed out with hoses by men wearing canister-type masks, without untoward incident.

\section{Discussion}

Recorded cases of acute paranitraniline poisoning are few. Hamilton (1929) quotes a fatal case from a dye works at Hoechst, where a man had worked for five hours in paranitraniline dust. Motashaw (1945) reported two cases in Bombay, one of which was fatal. These men pushed a hand-cart containing a leaky cask of paranitraniline a distance of eight miles, and on the return journey one became ill. The other placed him on the cart, which was still covered with the powder. Subsequently, the second man began to weaken, so both lay down on the pavement to sleep, and were found in a comatose condition several hours later. The first case died. Two further cases are described by this author from the records of the King Edward Memorial Hospital, Bombay, covering the previous ten years.

The incident described here well illustrates the ' lag' period before the onset of symptoms. The men finished work at 6 a.m. but did not appear at the hospital till mid-day. The hot, moist conditions in the hold of a ship in the Persian Gulf probably assisted the absorption of the toxic substance. Mean minimal temperatures at the time of the year are usually between $65^{\circ}$ and $90^{\circ} \mathrm{F}$., while the clothes and skins of the patients, being heavily coated with the dye, assisted continued absorption even after work had ceased. It is stated that a moderate degree of aniline poisoning will recover in about 24 hours, but that recovery from paranitraniline poisoning takes longer. Two of Motashaw's cases took four days to recover. The two cases recorded here had completely recovered in 24 hours, but the 'bosun, who was not at first severely affected, still had headache and recognizable cyanosis at the end of the same period of time. Jaundice has never been described in any form of aniline poisoning, but it is probable that the malarial hepato-splenitis existing in the fatal case was transformed into a toxic jaundice by the added strain of the attempt to deal with the poison. Scheff (1940) has shown that the liver plays a part in the metabolism of both aniline and its probable degradation product, $p$-aminophenol. The basic cause of the incident was lack of appreciation of the risk. The Master had had no warning that he carried a potentially toxic substance and the containers were not labelled.

\section{Summary}

The occurrence of paranitraniline poisoning in Persian dock labourers handling the dye in powder form in an enclosed space is described.

The intravenous injection of a concentrated solution of methylene blue brought about rapid relief of symptoms in three patients to whom it was administered.

A malarial hepato-splenitis in one case was transformed into a toxic jaundice by the action of the poison, resulting in death.

Ignorance of the hazard on the part of those responsible for handling the dye was due to lack of information.

\section{Acknowledgements}

I wish to record my gratitude to Dr. S. D. McClean, Chief Medical Officer to the Anglo-Iranian Oil Company, Limited, for permission to publish this article, and to Mr. E. R. Davies, Surgeon to the A.I.O.C., for advice and assistance.

\section{REFERENCES} Brandt, A. D. (1943). Manual of Industrial Hygiene, W. B. Saunders
Co., Philadelphia. Hamblin, D. O., and Mangelsdorff, A. F. (1938). J. Industr. Hyg,

Hamilton, A. (1929). Industrial Poisons in the United States, p. 501. Hunter, D. (1944). Industrial Toxicology. Clarendon Press, Oxford, Kobert, A. D., and Rambousek, H. (1913). Cited by Hamilton (1929).

Lewis, J. H., Wells, H. G., and Kobert, Rambousek (1920). I Industr. Hyg., 2, 249

Motashaw, M. D. (1945). Indian Physician, 4, 127.

Scheff, G. E. (1940). J. Pharm. and Exp. Therap., 70, 334. 